\title{
Las prácticas sociales cotidianas de jóvenes universitarios en la perspectiva de la ciudadanía ${ }^{1-2}$
}

\author{
José Rubén Castillo García ${ }^{3}$
}

\begin{abstract}
Resumen
En este documento se desarrollan dos aspectos diferentes y complementarios: primero, las concepciones en que se apoyan diversos pensadores para referirse a las prácticas sociales, y el segundo, muestra la aplicabilidad que tienen estos conceptos en la vida cotidiana de colectivos de jóvenes estudiantes universitarios de la ciudad de Manizales -Colombia-, lo cual evidencia mediante un estudio particular la aplicabilidad de nuestra propuesta teórica.

En principio se presenta un análisis teórico que permite deducir de las relaciones sociales y humanas, la vida cotidiana y a partir de éstas los sentidos con base en los cuales se deducen las connotaciones que les damos a las prácticas sociales. Estas últimas se evidencian desde cuatro aspectos, como estructuración de las acciones sociales, las formas de acción social, la discursividad que le sirve de modelo de regulación y las categorías que permiten leerlas a partir de los conceptos que emiten los sujetos de dichas prácticas.

Luego, se muestra la configuración de las prácticas sociales de los jóvenes universitarios, en la perspectiva de los asuntos de la ciudadanía, teniendo como base una disertación sobre el papel de los conceptos en calidad de cimientos del pensamiento y de la comunicación y del comportamiento humanos, los cuales parten del sentido común de los sujetos y permiten trascenderlos hacia los sentidos y significados que están en la base del mundo de la vida.
\end{abstract}

1 La base de este artículo es un capítulo de la investigación denominada “Configuración de ciudadanías juveniles en la vida cotidiana de estudiantes universitarios de Manizales", presentada por el autor para optar al título de Doctor en Ciencias Sociales, niñez y juventud. Universidad de Manizales - CINDE, 2006.

2 La vinculación del autor del texto al programa doctoral en Ciencias sociales, niñez y juventud, y la consiguiente aceptación de la propuesta de investigación que serviría de tesis, fue aprobada por el Comité de Rectoría de la Universidad Autónoma de Manizales mediante comunicación del 28 de julio de 2000. La investigación se desarrolló entre agosto de 2000 y noviembre de 2006.

3 Docente investigador de la Universidad Autónoma de Manizales, Magíster en Desarrollo Educativo y Social y Doctor en ciencias sociales, niñez y juventud, miembro del grupo de investigación en Ética y Política y coordinador de la línea de investigación en Competencias Ciudadanas de la Universidad Autónoma de Manizales. Dirección electrónica: jorca@autonoma.edu.co y jorca53@gmail.com 
Las prácticas sociales cotidianas de jóvenes universitarios en la perspectiva de la ciudadanía - José Rubén Castillo García

Al final del texto, se presentan algunas conclusiones que dan cuenta de las prácticas sociales de los jóvenes, inferidas a partir de sus narraciones, conceptos, hábitos y costumbres, tendientes a construir su condición de ciudadanos, en otras palabras, permiten ver las diversas maneras de ejercer dicha condición con sus diferentes matices.

Palabras clave: Relaciones sociales, Vida cotidiana, Mundo de la vida, Formas de acción social, Discursividad, Prácticas sociales, Ciudadanía, Jóvenes universitarios.

\begin{abstract}
This paper discusses two different and complementary aspects: first, the concepts underpinning various thinkers to refer to social practices, and the second shows the implementations of these concepts in everyday life of groups of young college students Manizales-Colombia-, which is evidenced by a study including the applicability of our theoretical proposal.

In principle presents a theoretical analysis to deduce the social and human relations, daily life and from these based on the senses which is deducted from the connotations we give to social practices. The latter was evident from four aspects such as structuring of social actions, forms of social action, which serves discursivity regulation model and the categories that can read from the concepts that emit the subject of such practices.

Then he shows the configuration of social practices of university students, in the perspective of the issues of citizenship, based dissertation on the role of concepts as foundations of thought and communication and human behavior, which leave common sense and allow individuals to transcend the senses and meanings that are the basis for the lifeworld.

At the end of the text, some conclusions that account for the social practices of young people, inferred from their narratives, concepts, habits and customs, tending to build their capacity as citizens, in other words, they allow to see the various ways to exercise this condition with its different nuances.
\end{abstract}

Key words: Social relations, Daily Life, World of life, Forms of social action, Discourse, Social practices, Citizenship, Young students. 


\section{Introducción}

Esta temática tiene su origen en el marco de tres componentes: primero, la praxis cotidiana en la que realizan la vida los sujetos, segundo, los significados y sentidos que ellos producen y reproducen a partir de las praxis sociales, teniendo como base las representaciones sociales y los imaginarios colectivos, y tercero, los aspectos que permiten la configuración de los sujetos en la perspectiva de las relaciones sociales humanas.

Partimos del supuesto teórico de que la configuración de las sociedades se produce a partir de los imaginarios colectivos y de las prácticas sociales, y que ambas tienen relación directa con las condiciones históricas (políticas, sociales, económicas y culturales) en que viven los colectivos. Esta configuración de las sociedades se haya referida a las circunstancias de la vida cotidiana. En razón de esto nuestras reflexiones se centran en dos aspectos: primero, establecer las concepciones y sentidos de las prácticas sociales, y segundo, la configuración de dichas prácticas, teniendo como base los conceptos emitidos por los jóvenes de las universidades de Manizales -Colombia-, lo cual evidencia la aplicabilidad de nuestra propuesta teórica.

\section{De las relaciones sociales humanas}

Todo ser humano cuando nace se encuentra con un mundo ya existente, independiente de él, que se convierte en un referente necesario e imprescindible que condiciona el desarrollo de cada persona e incide notablemente en la construcción de sus potencialidades, dependiendo de la manera como cada sujeto lleva a cabo el proceso de vinculación, de apropiación y de creación del entorno. Tal como lo indican Berger y Luckman (1978: 164):

El individuo no nace siendo miembro de una sociedad: nace con una predisposición hacia la socialidad, y luego llega a ser miembro de una sociedad. En la vida de todo individuo, por lo tanto, existe verdaderamente una secuencia temporal, en cuyo 
Las prácticas sociales cotidianas de jóvenes universitarios en la perspectiva de la ciudadanía - José Rubén Castillo García

curso el individuo es inducido a participar en la dialéctica de la sociedad. El punto de partida de este proceso lo constituye la internalización: la aprehensión o interpretación inmediata de un acontecimiento objetivo en cuanto expresa significado.

De lo dicho, podemos inferir que la construcción de la subjetividad y de la identidad de cada individuo se hace a partir de la ubicación de cada persona en el mundo, un mundo de significantes y significados, expuesto en el escenario de una cultura que le da sentido a las circunstancias que le presenta el medio social y cultural. Dicha construcción de los sujetos se enmarca en diferentes aspectos: la subsistencia, la socialidad, la relación con lo público y la construcción simbólica.

Este proceso se puede asumir como la adecuación, preparación, abono y cultivo del ser que va a ser coejecutor de la vida humana, y comprende dos componentes denominados internalización y externalización: en el primero, el mundo exterior a los sujetos se hace presente con todos sus significados y sentidos en las estructuras conceptuales de los sujetos y tiende a definir los parámetros mediante los cuales éstos construyen sus pautas de pensamiento tendientes a ubicar los comportamientos, actitudes y desempeños de cada persona; luego, el segundo, lleva al sujeto a manifestarse ante el mundo exterior, hacerse tangible frente al mismo y tal vez afectar el funcionamiento de la sociedad y condicionar la marcha de los fenómenos de ese mundo exterior. Este proceso mediante el cual nos expresamos los seres humanos e incidimos en el medio con el fin de adecuarlo para que satisfaga nuestras necesidades se ha denominado externalización o también objetivación, puesto que es el resultado de la acción de la persona en el mundo. Por esto, se da como un hecho que los actos humanos influyen en la forma y en los contenidos de la sociedad, y están atravesados por el mundo simbólico que le da forma.

La sociedad se configura, pues, mediante procesos que la producen y la reproducen. $Y$ en esos procesos interviene cada ser humano, por la interacción social y el intercambio de expresiones 
y de significados, en doble dirección, de la sociedad hacia cada persona y de ellas hacia la sociedad, de modo que es posible concluir que la sociedad produce al individuo y el individuo produce la sociedad.

En ese sentido, son múltiples las relaciones que establecemos los seres humanos en las sociedades para conservarnos, subsistir y reproducir el mundo donde vivimos. Estas relaciones constituyen la realidad específica en la cual nos inscribimos. Es importante destacar tres tipos de relaciones: en primer lugar, las que se originan en el contacto con la naturaleza a través del trabajo, en segundo lugar, las que se producen entre los humanos con base en las diversas formas de interacción, y en tercer lugar con los signos, significados, contenidos y significaciones que se producen a partir de los procesos comunicativos.

Cuando se hace referencia a las relaciones y las realidades que construimos los seres humanos en las sociedades, se deben considerar las condiciones históricas en las cuales éstas se llevan a cabo, dado que les dan razón y significado a su existencia. Lo histórico, trasciende las cronologías e incluso las leyes de la evolución social, puesto que se enmarcan en los modos de producción, las formaciones sociales, y demás determinantes económicos, políticos, sociales y culturales.

En este proceso de construcción mutua de individuo y sociedad, se distingue lo propio, lo particular, lo que constituye la esfera del yo, donde se constituyen las subjetividades y las identidades, y lo diferencia de aquello que le corresponde a la especie, es decir lo genérico. Los procesos de construcción de los seres humanos como seres culturales se realizan en la vida cotidiana, en calidad de escenario donde tenemos nuestras vivencias, elaboramos experiencias y generamos alternativas de acción relacionadas con los eventos que acompañan nuestro quehacer como seres individuales, tanto en función de nosotros mismos, como en proyección hacia los demás. De esta manera, los actos de la vida cotidiana de las personas quedan latentes en el espacio colectivo 
Las prácticas sociales cotidianas de jóvenes universitarios en la perspectiva de la ciudadanía - José Rubén Castillo García

y se convierten en un referente para los procesos de comunicación y de intercambio social.

\section{La vida cotidiana}

En la vida cotidiana se expresan las actividades sociales, que reproducen tanto a los sujetos particulares como a los colectivos. La vida humana es el dominio del comportamiento de las personas, que deriva de la división social del trabajo y de la especialización en sus desempeños. A partir de estas dos categorías se entiende el sentido con el cual se realizan las acciones humanas, se materializan los comportamientos individuales, sus expresiones, significaciones, habilidades, intereses, motivaciones y valores. Estos aspectos permiten a cada individuo proyectarse a los demás y llevar a cabo sus interacciones que le asignan un puesto en el funcionamiento del todo social.

La vida cotidiana es una realidad construida desde la presencia del cuerpo físico en el aquí y de las condiciones en las cuales vive el ahora. Según Agnes Heller (1991: 21 y 22) tiene que ver con que:

El particular nace en condiciones sociales concretas, en sistemas concretos de expectativas, dentro de instituciones concretas. Ante todo debe aprender a "usar" las cosas, apropiarse de los sistemas de usos y de los sistemas de expectativas, esto es, debe conservarse exactamente en el modo necesario y posible en una época determinada en el ámbito de un estrato social dado. Por consiguiente, la reproducción del hombre particular es siempre reproducción de un ser histórico, de un particular en un mundo concreto.

En los procesos de interacción social concretados en la vida cotidiana se genera la necesidad de formalizar pautas y acuerdos que permitan la convivencia. A partir de este principio, la sociedad expresa y refleja el conjunto de normas, organizaciones, estructuras sociales, formas de ver y de vivir en el mundo con base en las cuales se hace posible la convivencia. 
El ejercicio de la vida cotidiana produce un conjunto de significados, mediante los cuales, en su proyección hacia los demás, se construyen los imaginarios colectivos y las representaciones sociales. Pero estas construcciones colectivas, de acuerdo con Melich (1996: 35.), surgen de manera espontánea, sin una mediación consciente:

... esa esfera $u$ horizonte, espacio temporal en el que transcurren las vivencias, pensamientos y acciones humanas de orden espontáneo o irreflexivo, en él los actos tienen lugar maquinalmente dado que muy pocas veces actuamos racionalmente en la cotidianidad.

En ese espacio no deliberado, se mueve el fenómeno de la cultura, entendido como el universo de lo significativo y de los sentidos en los cuales está inserta toda acción del ser humano. $\mathrm{Y}$ en ese espacio arreflexivo, se genera el sentido común (doxa para los griegos) como el abordaje automático del mundo que parte de los supuestos culturales sin una mediación crítica. En esta forma, el sentido común tiene las siguientes características:

Da por establecido que el mundo son sus objetos, es decir, se centra en lo observable, lo perceptible, y lo experimentable. Asume que las cosas son lo que parecen ser, se dan por sentadas, se supone que son así.

Se refiere a las experiencias válidas, bien sean propias o de los demás. Si se producen los resultados esperados, se asume que estas funcionan, y por ende se les da toda la credibilidad posible.

Los sujetos son pragmáticos y espontáneos, por tanto hay reticencias hacia los intereses teóricos, de ahí que los acontecimientos se den por entendidos fácilmente.

La cultura popular se expresa con base en el sentido común y se apoya en razonamientos prácticos. Por tanto para descubrir la realidad que se aborda desde la vida cotidiana, es necesario 
Las prácticas sociales cotidianas de jóvenes universitarios en la perspectiva de la ciudadanía - José Rubén Castillo García

consultar tópicos que tengan de base el sentido común de la población, es decir, que se apoyen en la opinión de las personas que las realizan. De esta manera, se puede dar cuenta de lo que hacen, los motivos de sus acciones, las razones en que se apoyan sus decisiones, y en ellas fluyen las lógicas que orientan el mundo de la vida de las personas.

Ubicar a las personas en el mundo de la vida, lleva a centrarnos en las esferas del desarrollo humano. Estas esferas comprenden varios aspectos: social (relación con los otros), cultural (formas de ser, pensar, sentir, actuar), personal (significación como ser único), económica (subsistencia), y política (vida colectiva, la toma de decisiones).

Este es el ámbito donde ocurre y transcurre la vida normal de los seres humanos, teniendo como marco de referencia el mundo de los significados y los sentidos. Allí, igualmente, surgen los horizontes donde se da la vida, implicando en ello las relaciones de los sujetos con el ambiente natural.

La realidad vista desde esta perspectiva tiene dos dimensiones: objetiva (base material, desde la cual se perciben las condiciones de existencia) y subjetiva (comprende los significados, desde donde se definen las necesidades), entre las dos y con la interacción entre ambas, los sujetos humanos hacemos presencia en el mundo de la vida y logramos el reconocimiento de nuestra existencia en el mundo colectivo y compartido.

Para abordar el estudio de los mundos que viven los jóvenes, y las prácticas que realizan, partimos de la vida cotidiana para develar su realidad. A partir de ella, se puede recuperar el modo en que cada uno de los colectivos juveniles se construye y significa sus propios procesos de autoidentificación y de construcción social. Se trata de penetrar en la producción cultural, para efectos de comprender lo que quieren comunicarle a la sociedad, a todos los niveles, incluidos los aspectos políticos. En términos de Rossana Reguillo (2000: 1), para el caso de las prácticas juveniles, se trata de: 
Analizar, desde una perspectiva sociocultural, el ámbito de las prácticas juveniles, hace visibles las relaciones entre estructuras y sujetos, entre control y formas de participación, entre el momento objetivo de la cultura y el momento subjetivo. Intentar comprender los modos en que cristalizan las representaciones, valores, normas, estilos, que animan a los colectivos juveniles, es una apuesta que busca romper con ciertos "esteticismos" y al mismo tiempo con esa mirada "epidemiológica" que ha pesado en las narrativas construidas alrededor y sobre los jóvenes.

El enfoque sociocultural implica, entonces, historicidad, es decir, miradas de largo plazo y, necesariamente, una problematización que atienda lo instituyente, lo instituido y el movimiento.

La mirada sobre las prácticas de los jóvenes que nos aproxime a las maneras como producen y reproducen las relaciones sociales y a los contenidos de sus expresiones ciudadanas, parte de la pregunta por sus alternativas de vida y los usos que hacen de su entorno. Y, como se ha dicho, esto sólo es posible penetrando en sus prácticas sociales.

\section{Las prácticas sociales}

Las prácticas sociales se piensan desde varios ángulos, entre los cuales se destacan dos formas básicas de entenderlas. De un lado, se asumen como el resultado de la aplicación de los conocimientos teóricos que los sujetos han obtenido previamente y que tratan de aplicarlos para efectos de hacerlos tangibles en la realidad, es decir, mediante las prácticas se objetiva el conocimiento de los sujetos en el mundo de la vida. Desde este punto de vista, se entienden las prácticas sociales como maneras de hacer y formas de proceder dentro de un entorno específico con finalidades definidas.

Por otro, se leen las prácticas sociales como resultado de la acción discursiva de los sujetos, teniendo como base las condiciones y circunstancias en las cuales se produce dicho discurso. 
Las prácticas sociales cotidianas de jóvenes universitarios en la perspectiva de la ciudadanía - José Rubén Castillo García

Esta última perspectiva concibe a los sujetos vinculados a una cultura de la cual se nutren y a partir de ella construyen sus criterios y pautas de acción para configurar la realidad. Desde allí, se ven las prácticas como el resultado de la definición de reglas y de lógicas que permiten ordenar la existencia de los sujetos con fundamento en criterios que configuran sus acciones.

\subsection{Las prácticas como formalización de las acciones sociales}

Con base en lo planteado por Ritzer (s.f.) con respecto al papel de las prácticas sociales en la configuración de la sociedad, se encuentra una relación importante entre la estructura social y las acciones que enmarcan la génesis de las prácticas humanas. Estas prácticas, según este autor, tendrían dos características básicas: primero, la recurrencia, puesto que son el resultado de la reiteración de las acciones donde se evidencia su existencia, y segundo, el orden, que alude a la forma y la estructura de las acciones.

Queda por aclarar el papel que puede jugar la conciencia del sujeto en la realización de las prácticas y la función que cumple el colectivo social en el desempeño de los sujetos. La hipótesis que está por explorar plantea la necesidad de que los investigadores sociales centren su atención en las prácticas y en las estructuras que se evidencian de ellas, antes que en las experiencias individuales de los sujetos o en las formas genéricas que tiene la totalidad social.

$\mathrm{Al}$ abordarse la discusión sociológica sobre los niveles de injerencia de los sistemas sociales en el desarrollo de las prácticas humanas, nos oponemos al punto de vista de algunos autores que exageran la determinación de la realidad externa sobre las prácticas sociales. Reconocemos que esta las condiciona, pero que los deterministas desconocen las posibilidades de las personas y los conglomerados humanos de optar y de asumir posiciones propias. Por eso, planteamos que los sujetos pueden distanciarse de los controles y de las constricciones que derivan de las propiedades 
estructurales de los sistemas sociales, puesto que, según él, estas no son jaulas de hierro, tal como lo propone Weber (1969).

\subsection{Las formas de acción social}

Entre quienes han planteado criterios para caracterizar las acciones sociales, destacamos a Max Weber y Jürgen Habermas, quienes abordan desde diferentes orillas las formas de la acción social. Paul Ricoeur (1973-1975: 97-122) expresa el pensamiento weberiano de la siguiente manera:

Para Max Weber se da acción social cuando el comportamiento humano es significativo para los agentes individuales y cuando el comportamiento de un individuo se orienta en función de otro. La idea de relación social añade a este doble fenómeno de significación de acción y de orientación mutua la idea de estabilidad y de una previsibilidad de un sistema de significaciones. Pues bien, es en este nivel del carácter significativo mutuamente orientado y socialmente integrado de la acción, donde aparece en toda su originalidad el fenómeno ideológico. Está ligado a la necesidad que tiene un grupo social de darse una imagen de sí mismo, de representarse, en el sentido teatral de la palabra, de ponerse en escena.

Weber (1969: 62 y ss.) considera que existen varios tipos de acción social, derivados de la orientación que les asignan los actores sociales a sus prácticas, en primer lugar, en función de las expectativas de logro de sus fines; en segundo lugar, de los valores y las relaciones que tienen estos con respecto de los resultados; en tercer lugar, con el papel que cumplen los afectos en los comportamientos de las personas; y en cuarto lugar, la función que realizan las costumbres sociales en el origen de las acciones de los sujetos.

En el primer caso, los actores sociales se desempeñan con base en los fines que desean alcanzar y de las expectativas que tienen de lograrlos. En este sentido, utilizan los "medios" nece- 
Las prácticas sociales cotidianas de jóvenes universitarios en la perspectiva de la ciudadanía - José Rubén Castillo García

sarios para orientar las acciones. Esta forma de acción social da cuenta de las conductas humanas deliberadas que los sujetos definen para efectos de buscar los diferentes fines.

El segundo tipo de acción social enunciado por Weber alude a los valores en que se apoyan los diferentes campos de la vida para el logro de los fines. Dichos valores pueden ser éticos, estéticos, religiosos, políticos e ideológicos. En esta forma de acción social, se privilegian los méritos que se les puede otorgar a la conductas de las personas, al comportamiento y al desempeño de los sujetos, antes que a los resultados mismos, como en el caso anterior.

El tercer tipo de acción social analizado por Weber se refiere a las acciones sociales motivadas por estados sentimentales actuales. Según él, los comportamientos y prácticas sociales humanas pueden derivar de aspectos afectivos, que determinan formas de acción social.

El cuarto tipo de acción social, la denomina tradicional, pretendiendo mostrar que en estas formas de realizar las prácticas sociales, se privilegian las tradiciones y las costumbres como motivos que legitiman la acción de los sujetos y cuyo arraigo origina determinado tipo de conductas en el mundo social.

Por otro lado, Habermas (1987: 147-196), de manera similar que Weber, plantea que las acciones humanas tienen cuatro tipos de expresiones, sin embargo, él tiene en cuenta para su clasificación los intereses, motivaciones e intencionalidades que llevan los sujetos al momento de ejecutar sus acciones. Ellas son la teleológica, la orientada por normas, la dramatúrgica y la acción comunicativa.

La acción teleológica, es propia de la participación de las personas en los procesos técnicos. Se deriva de la tradición de las ciencias naturales, puesto que en estas se ha privilegiado la racionalidad que puede existir entre los medios y sus fines, para lo cual se propone definir los fines y luego los medios mediante los cuales se espera conseguir determinados resultados. De manera similar que Weber, los fines son una referencia importante 
para caracterizar este tipo de acción, pero Habermas privilegia los intereses antes que las expectativas. Este tipo de acción, en el campo de la ciencia, implica que para medir el nivel de logro, se consideran conceptos de verdad, objetividad y de éxito, además de que el sujeto se relaciona básicamente con objetos.

En la acción regulada por las normas, el sujeto se desempeña en lo social, y por tanto, el contexto de sus acciones son la ética y la política. En este tipo de acción, es importante la rectitud, dado que el sujeto se relaciona con otros sujetos y se trata de apoyarse en las normas para regular su convivencia. Dichas normas son susceptibles de ser cumplidas y de ser cuestionadas, pero ante todo deben ser respetadas, en tanto obedezcan a las necesidades que puedan afectar la vida colectiva. Este tipo de acción difiere de las expresadas por Weber, dado que éste se apoya más en los valores, en los afectos y sentimientos, y en las costumbres, que en las normas de regulación social.

Cuando los sujetos humanos se relacionan con los demás al poner en común sus mundos subjetivos, cuando intercambian sus contenidos y significaciones, se produce la acción dramatúrgica. En ella, las personas se relacionan a partir de lo privado, que al expresarlo ante los demás se pone en discusión y se hace público; es lo que hace un artista cuando proyecta su mundo privado y lo somete a confrontación. En este tipo de acción es importante la veracidad, la sinceridad y la autenticidad en los contenidos que manifiestan los sujetos, dado que son criterios que permiten establecer el carácter de la relación entre el lenguaje y la acción, puesto que ellos se interpretan recíprocamente.

Para aclarar la función que cumple este tipo de acción social es importante que se tenga en cuenta que el lenguaje es el medio mediante el cual se puede aclarar el sentido de las acciones humanas. Aquí de nuevo hay distancia con respecto de lo expresado por Weber, en tanto en esta se hace énfasis en los contenidos y significados de las acciones, vistos desde los sentidos que se pueden percibir a partir de la lingüística. 
Las prácticas sociales cotidianas de jóvenes universitarios en la perspectiva de la ciudadanía - José Rubén Castillo García

$\mathrm{Al}$ caracterizar la acción comunicativa, se privilegia la posibilidad que tienen los sujetos de establecer acuerdos mutuos, teniendo como base el interés por lograr entendimiento entre ellos. Este modelo de acción es la base de los otros modelos, porque considera que a partir de él se entiende el sentido de los otros. Aquí se hace necesario integrar el significado de las relaciones interpersonales con la pretensión de la validez que pueda mediar entre ellas, para efectos de interpretar las acciones humanas. No sobra aclarar que desde este punto de vista se piensa que para interpretar una acción es necesario tratar de establecer los motivos que tuvo un individuo para actuar.

Según Ritzer (s.f.: 182, 184 y 185), es necesario aclarar que para Habermas es diferente hablar de la acción comunicativa y del discurso, aclaración que para este caso, sirve para dimensionar el sentido que tiene este tipo de acción:

Habermas distingue entre la acción comunicativa... y el discurso. Mientras la acción comunicativa se produce en la vida cotidiana, el discurso es... "esa forma de comunicación alejada de los contextos de la experiencia y la acción cuya estructura nos asegura: que la condición de validez de las afirmaciones, recomendaciones o advertencias constituye el objeto exclusivo de la discusión; que los participantes, temas y aportaciones no conocen otro límite que el que se refiere a la meta de la comprobación de la validez en cuestión; que no se ejerce fuerza alguna salvo la de un argumento mejor; y que se excluyen todos los motivos excepto el de la búsqueda cooperativa de la verdad." (Habermas, 1975: 107-108).

En la acción comunicativa... las acciones de los agentes implicados en ella se coordinan no mediante cálculos egocéntricos del éxito sino mediante actos para lograr la comprensión. En la acción comunicativa los participantes no se orientan principalmente hacia su éxito; persiguen sus metas individuales con la condición de que sean capaces de armonizar sus planes de acción sobre 
la base de definiciones comunes de las situaciones." (Habermas, 1984: 286; cursivas añadidas).

“El consenso surge teóricamente en el discurso (y preteóricamente en la acción comunicativa) cuando se dan cuatro condiciones de validez aceptadas por todos los participantes. Primera, la exposición del hablante ha de ser aceptadamente comprensible. Segunda, las proposiciones ofrecidas por el hablante han de ser verdaderas; es decir, el hablante ha de ofrecer un conocimiento fiable. Tercera, el hablante ha de ser veraz en sus proposiciones; el hablante es fiable. Cuarta, el hablante ha de disponer del derecho a expresar esas proposiciones. El consenso surge cuando se dan y se aceptan estas cuatro condiciones de validez; se rompe cuando se ponen en cuestión una o varias (por ejemplo; cuando se cuestiona el derecho del hablante a expresar ciertas proposiciones). Volviendo a algo que ya hemos planteado antes, en el mundo moderno hay fuerzas que distorsionan este proceso, que impiden la emergencia del consenso, y que deben ser eliminadas para alcanzar la sociedad ideal de Habermas.

\subsection{Las prácticas sociales como resultado de la discursividad}

Diversos autores piensan que las prácticas son el resultado de la construcción de discursos, y consideran que estos son los que permiten no sólo denominar sino delimitar y configurar los objetos de los cuales se habla. Argumentan que, con base en estos, se definen las leyes mediante las cuales se formalizan dichos objetos. En este caso, se considera que es posible ampliar este criterio a las prácticas sociales, en tanto estas pueden ser definidas como objeto de indagación.

Es preciso, pues, distinguir dos tipos de comunicación: por un lado, la que ocurre en la vida cotidiana, y por otro, la que se constituye como discurso propiamente dicho. En este sentido, Moser (1978: 124), señala el alcance de cada una y la diferencia entre ambas: 
Las prácticas sociales cotidianas de jóvenes universitarios en la perspectiva de la ciudadanía - José Rubén Castillo García

... distinguimos entre la comunicación diaria y el discurso. Desde este punto de vista el comportamiento comunicativo como una actividad diaria no es nada distinto a nuestras charlas corrientes o conversaciones en las cuales damos por sentadas las reglas y normas que guían nuestro comportamiento comunicativo. En oposición a esto, el "discurso" -tal como se define en la filosofía alemana- significa una manera de comunicación donde se trata de cuestionar la realidad social existente, sus reglas construidas interiormente, las normas y los prejuicios. En un discurso tratamos de revelar la estructura contradictoria de nuestro mundo común con el fin de elaborar las posibilidades de cambiarlo.

Estos conceptos sirven de punto de partida a Foucault, que considera que cuando se trata de referirse a las cosas, se debe hacer alusión al conjunto de reglas que permiten configurar los objetos, pero en la perspectiva de trascender los análisis lingüísticos, buscando con ello que las miradas sobre este asunto vean más allá de los signos y de los significados que denotan los objetos. Aunque se tengan en cuenta las representaciones de los contenidos de los objetos y se deba partir de ellas, es necesario que los investigadores se remitan a los sentidos sistemáticos, puesto que es a partir de ellos como se puede acceder a las comprensiones en torno de los objetos a los cuales se hace referencia.

Óscar Fernández (s.f.), en su análisis sobre Foucault, al analizar las prácticas sociales, indica cómo estas se constituyen cuando se tienen en cuenta, entre otros, los siguientes criterios que se pueden asumir como supuestos básicos para efectos de comprender el papel de los discursos en la configuración de la realidad:

Primero, que las palabras están en el origen de los objetos. Los discursos no son un conjunto de signos que remiten a contenidos o representaciones; sino "prácticas que forman sistemáticamente los objetos de que hablan". Segundo, un discurso es irreductible a la lengua y a la palabra, (¿por qué?), porque es algo más que un con- 
junto de palabras para designar cosas. ¿El discurso se diferencia de la lengua y de la palabra?. No, diría Foucault, es existencia muda de una realidad, recurso a la plenitud viva de la experiencia, uso normativo de un vocabulario, descripción de un vocabulario, las palabras están tan deliberadamente ausentes como las cosas.

... Surge la pregunta: ¿qué es una práctica discursiva? Es el lugar donde se forman o deforman los únicos objetos accesibles al pensamiento. Responder nos convoca a otra reflexión.

No obstante, para comprender las formas que permiten la configuración de las prácticas, es necesario establecer el orden de los significados para efectos de evidenciar los objetos de los cuales se hace mención. Este orden es propio de la actividad consciente de las personas, en tanto es el resultado de poner en juego sus argumentos. Allí hacen presencia los parámetros que los sujetos han elaborado a lo largo de su existencia, de los modelos de pensamiento a partir de los cuales orientan esos sujetos sus miradas para efectos de hacer lecturas de la realidad.

Además de estas visiones ordenadoras del mundo que cumplen con la misión de darle sentido a la realidad en la cual se desenvuelven los sujetos, estos suelen apoyarse en la necesidad de indagar sobre las condiciones históricas en las cuales se ejercen las prácticas discursivas, pensando no sólo en la sucesión de acontecimientos en el tiempo sino en las circunstancias que las han hecho posibles, los conflictos, los intereses, las motivaciones de los sujetos que las han acompañado e incluso las han construido, pero que adquieren sentido y significación en razón de los espacios culturales en los cuales se vivencian.

Fernández (s.f.) señala cómo estas condiciones históricas permiten dar cuenta tanto del modo de ser de las cosas como de asuntos epistémicos que pasan por evidenciar la existencia del orden, la relación con el contexto en el cual se configura y que da forma y posiblemente vida a la realidad de la cual se habla. 
Las prácticas sociales cotidianas de jóvenes universitarios en la perspectiva de la ciudadanía - José Rubén Castillo García

... El orden de las cosas que nosotros consideramos como su ley intrínseca "sólo existe a través de la retícula de una mirada, una atención, un lenguaje. Este pensamiento tiene importantes consecuencias metodológicas. No tenemos una "experiencia pura del orden", nunca topamos con el ser bruto del orden. El orden que supone ser la base positiva sobre la que se construyen las teorías no está inscrito en las cosas mismas, sino que es instaurado por las prácticas discursivas que forman el a priori histórico de un momento cultural.

... "el modo de ser de las cosas y del orden que las distribuye, y así las ofrece al saber", se altera de una epistemología a otra. Así, "una historicidad profunda penetra en el corazón de las cosas". No existe un orden objetivo e inmutable que se sustente en la "estructura metafísica de lo concreto". El orden varía según los diferentes momentos de la cultura occidental. Diferencia que se va a dar a través de todas las epistemes del pensamiento occidental. Si nos valemos de la noción de episteme, para Foucault esta no es una visión del mundo, o una estructura del pensamiento, ni siquiera un tramo histórico común a todos los conocimientos de una época, sino el "conjunto de relaciones capaces de unir, en una época dada, las prácticas discursivas que dan lugar a figuras epistemológicas, a ciencias, y eventualmente, a sistemas formalizados.

... Mientras la episteme es un dispositivo específicamente discursivo, que tiene que ver con la disposición de los enunciados dentro de una teoría científica. El dispositivo que después conforma, está determinado por las prácticas sociales y el poder que las atraviesa, a través de formaciones discursivas y no discursivas. Para el pensamiento clásico, lo discursivo sería el soporte de la institución, mientras que para Foucault todo lo que el individuo aprende y que lo constriñe.

De esta manera, las prácticas sociales se apoyan en varios aspectos: primero, cuando los conocimientos que orientan las prácti- 
cas derivan del sentido común, estas expresan lo que acontece en la vida cotidiana; segundo, ellas se realizan en unas condiciones históricas determinadas, dado que tienen sus raíces en instancias sociales y culturales; tercero, las relaciones que se configuran se encuentran atravesadas por las expresiones de poder que fundamentan las acciones sociales que ellas estructuran; cuarto, se manifiestan en los imaginarios colectivos y en las representaciones sociales de los sujetos y de los grupos sociales; y quinto, se refieren a los diferentes campos de la realidad social, entre ellos la ciudadanía.

En un nivel más específico, las formas y los contenidos que permiten configurar las prácticas, tienen que ver con los siguientes aspectos:

Primero, las prácticas se objetivan, es decir, se expresan en conjuntos de actos, procedimientos y acciones, que se hacen tangibles en lo que hacen las personas tanto a nivel particular como colectivo. Se evidencian en hechos y producen obras donde las personas hacen uso de sus cualidades, artes o facultades. Ellas reflejan, es decir, objetivan lo que son las personas, en sí mismas.

En segundo lugar, las prácticas sociales corresponden a las formas, artes, modos o maneras (viene de mano) de realizar los actos, es decir que se refiere a los métodos con que se realizan dichos actos. Esto ocurre en el conjunto de operaciones, o en las múltiples maneras de actuar de las personas en la vida cotidiana. Además, comprende lo que determina la acción, la cualifica, le da forma y condiciona la práctica, y por eso incluye los estilos con que se hacen las cosas, la creatividad, la intensidad del trabajo y el esfuerzo, en cuya base están los caracteres con que se configura la labor del ser humano. De esta manera, lo que se hace corresponde a esa cosa y no a otra.

Los Estilos se asumen como las marcas características en las formas de hacer o de decir. Ellos configuran los particulares modos de ser y las identidades en la acción. Son el sello característico que le imprimen los sujetos a sus prácticas. 
Las prácticas sociales cotidianas de jóvenes universitarios en la perspectiva de la ciudadanía - José Rubén Castillo García

El modo es un molde, una forma propia diferente de otras. Mediante las formas de su actuar, el ser humano va formalizando su existencia y moldeando su vida. Además de configurar un modo de ser particular tanto como individuo independiente y como parte de las comunidades culturales.

En tercer lugar, puesto que las prácticas que se realizan en la vida cotidiana se repiten, llevan a las regularidades y al uso continuado. Al repetir actos de la misma especie vamos adquiriendo costumbres y hábitos, que se manifiestan en acciones continuas o discontinuas. Usualmente, se asumen las costumbres y los hábitos como dos conceptos iguales, pero mirando en detalle, encontramos que son conceptos diferentes.

Mientras los hábitos se refieren a los tipos de acciones, de decisiones, modos de comportamiento y de pensar que llegan a ser parte de nuestras maneras de ser, las costumbres se ubican en el campo de los usos sociales, referidos a las formas en que unas personas se apropian de las obras de otros y las aprovechan para realizar sus acciones, éstas cobran significación porque son reconocidas a través de las prácticas. Las costumbres se ubican también en los manejos de procedimientos, de formas de acción que marcan el ritmo de vida de las personas.

Las prácticas hacen referencia a los órdenes o regulaciones que se establecen a partir de los hábitos y de las costumbres.

Cuarto, el escenario donde se ejecutan las prácticas sociales es la vida cotidiana, puesto que allí es donde se configura el ser humano. Es el ambiente y las condiciones en que se realiza la vida. Las prácticas organizan lo cotidiano, en tanto que allí se producen las lógicas, las normas de convivencia y se efectúan los actos individuales, singulares y particulares de las personas. Además, enmarcan las relaciones entre los seres humanos y el mundo en que vivimos, en el ámbito de la cultura.

En quinto lugar, los actores que realizan las prácticas, en nuestro caso los estudiantes universitarios. 
En sexto lugar, el carácter de las prácticas, deviene del tipo de mediaciones y de cómo éstas se manifiestan, el tipo de lenguaje, los discursos y las narraciones, a partir de los cuales se definen las significaciones y los sentidos de las acciones, los niveles de imaginación, conciencia o inconsciencia. Allí se articulan las comprensiones acerca de los discursos práxicos, es decir, de aquellos que buscan interpretar las reflexiones que se hacen en torno de las expresiones relacionadas con las acciones y los hechos, lo cual sin duda sirve para mostrar lo que somos y lo que hacemos.

Séptimo, la configuración de las prácticas se estructura con base en reglas, lógicas y ordenamientos. Aparecen como fruto de esquemas de operaciones que dan coherencia a las acciones, y esas coherencias son razonables cuando las prácticas que se establecen derivan de la utilidad, de la conveniencia y de su oportunidad.

Es importante tener en cuenta que esas estructuras son multiformes, fragmentadas, convergentes y divergentes, son cambiantes y diversas, obedecen a actos individuales y colectivos, y además se hallan referidas a determinadas situaciones que, aunque la configuración de las prácticas está condicionada por las reglas y estructuras, las crean y son creadas por ellas, también se da la posibilidad de generar nuevas expresiones de prácticas.

A un nivel más complejo, aparece lo que Bourdieu denomina habitus, que él define como sistemas de estructuras estructurantes, de disposiciones durables, trasladables, principios generadores y organizadores de prácticas y representaciones, sistemas de esquemas generadores, independientes con respecto de las determinaciones que provienen del exterior.

Por último, las prácticas son el resultado de las intencionalidades y de los fines que orientan esos procedimientos ordenadores, en el marco de las relaciones entre los individuos y la comunidad, bajo el amparo de la cultura en que viven. 
Las prácticas sociales cotidianas de jóvenes universitarios en la perspectiva de la ciudadanía - José Rubén Castillo García

Esas prácticas contribuyen a conservar o a transformar las culturas, pero a su vez, esas culturas inciden en la conservación o en la transformación de las prácticas. De esta manera, se convierten en modeladoras y constructoras de la historia.

\subsection{Las categorías que permiten leer las prácticas sociales}

\begin{tabular}{|c|c|c|}
\hline Categorías & SubCATEGoRÍAs & DesCRIPCIÓN \\
\hline \multirow[b]{4}{*}{ Contexto } & Vida cotidiana & $\begin{array}{l}\text { Escenario donde las personas llevan a cabo sus vidas, } \\
\text { construyen vivencias, elaboran experiencias y generan } \\
\text { alternativas de acción relacionadas con los eventos que } \\
\text { les acompañan en su quehacer como seres individuales, } \\
\text { tanto en función de sí mismos, como en su proyección } \\
\text { hacia los demás. }\end{array}$ \\
\hline & $\begin{array}{l}\text { Condiciones } \\
\text { históricas }\end{array}$ & $\begin{array}{l}\text { Circunstancias ubicadas en el tiempo y el espacio, a } \\
\text { partir de las cuales actúan los sujetos individuales y } \\
\text { los colectivos. }\end{array}$ \\
\hline & \begin{tabular}{|l} 
Relaciones \\
sociales
\end{tabular} & $\begin{array}{l}\text { Vínculos que se establecen entre las personas y que } \\
\text { permiten la conformación de los colectivos. }\end{array}$ \\
\hline & $\begin{array}{l}\text { Imaginarios } \\
\text { colectivos y } \\
\text { representacio- } \\
\text { nes sociales }\end{array}$ & $\begin{array}{l}\text { Imaginarios colectivos: conjunto de significaciones } \\
\text { compartidas que definen y estipulan lo que para una } \\
\text { sociedad es lo valorado y lo rechazado, lo normal y lo } \\
\text { patológico, lo que es "real" y aquello que no lo es, lo } \\
\text { que tiene sentido y lo que no lo tiene, lo cuestionable } \\
\text { y lo imposible de ser siquiera pensado... son elemen- } \\
\text { tos cohesionadores que permiten el entendimiento y } \\
\text { la comprensión entre las personas. Sirven de soportes } \\
\text { sociales sin los cuales no se puede organizar ninguna } \\
\text { sociedad. } \\
\text { Representaciones sociales: Son de cada individuo o } \\
\text { grupo social, expresan su apropiación del mundo exte- } \\
\text { rior. Son el conjunto de actitudes, motivaciones, creen- } \\
\text { cias, opiniones, concepciones, postulados, imágenes, } \\
\text { sistemas de valores, ideas, explicaciones y prácticas } \\
\text { que, originados en la vida diaria, en los procesos inter- } \\
\text { subjetivos de acción y comunicación, guían la acción } \\
\text { social. }\end{array}$ \\
\hline
\end{tabular}




\begin{tabular}{|c|c|c|}
\hline Categorías & SUBCATEGORÍAS & DESCRIPCIÓN \\
\hline & $\begin{array}{l}\text { Campo de la } \\
\text { realidad social } \\
\text {-ciudadanía- }\end{array}$ & $\begin{array}{l}\text { Ámbito de la realidad en donde se observan y perci- } \\
\text { ben las prácticas sociales. En este caso la ciudadanía. } \\
\text { Ciudadanía: forma "inventada" de ejercer la sociali- } \\
\text { dad de las personas en el seno de la sociedad regulada } \\
\text { jurídicamente. Allí se recoge y garantiza a los indivi- } \\
\text { duos derechos como la igualdad, libertad, autonomía } \\
\text { y la participación. Es una forma de ser persona en } \\
\text { sociedad. Es una construcción histórica, cuya esencia } \\
\text { radica en comprendernos y respetarnos como libres, } \\
\text { autónomos e iguales, al tiempo que se vive con otros. } \\
\text { Condición de la que se deriva una forma de percibirse } \\
\text { a sí mismo en relación con los demás. }\end{array}$ \\
\hline \multirow{8}{*}{$\begin{array}{l}\text { Configuración } \\
\text { de las } \\
\text { prácticas }\end{array}$} & Objetivaciones & $\begin{array}{l}\text { Actos, procedimientos, acciones y conjuntos de accio- } \\
\text { nes que hacen tangibles las prácticas sociales. }\end{array}$ \\
\hline & Formas & Artes, maneras de hacer las cosas, estilos. \\
\hline & Regularidades & Hábitos y costumbres. \\
\hline & Escenario & $\begin{array}{l}\text { Ambiente en el cual se realizan las prácticas sociales. } \\
\text { En nuestro caso, la vida cotidiana. }\end{array}$ \\
\hline & Actores & $\begin{array}{l}\text { Los que realizan las prácticas sociales. Estudiantes uni- } \\
\text { versitarios de pregrado. }\end{array}$ \\
\hline & $\begin{array}{l}\text { Tipo de } \\
\text { lenguaje }\end{array}$ & $\begin{array}{l}\text { Expresiones, mediante las cuales se manifiestan los } \\
\text { contenidos de las prácticas sociales. }\end{array}$ \\
\hline & Configuración & $\begin{array}{l}\text { Lo que le da forma a las prácticas sociales: reglas, lógi- } \\
\text { cas, procedimientos, coherencias. }\end{array}$ \\
\hline & $\begin{array}{l}\text { Intencionali- } \\
\text { dades }\end{array}$ & $\begin{array}{l}\text { Fines, lo que interesa, lo que se busca con la realización } \\
\text { de las prácticas. }\end{array}$ \\
\hline
\end{tabular}

\section{La configuración de las prácticas en ciudadanía de los estudiantes universitarios de Manizales (Colombia)}

\subsection{De los conceptos}

Los conocimientos de los seres humanos, expresados mediante conceptos, representan muchas de las condiciones y circunstancias en las cuales ejercemos nuestra existencia. Estos pensamientos tienen diferentes formas y niveles para lograr ese propósito. En principio, se puede decir que hay varios momentos en el desarrollo del pensamiento que permite la formación de los conceptos. 
Las prácticas sociales cotidianas de jóvenes universitarios en la perspectiva de la ciudadanía - José Rubén Castillo García

La generalización y la formación de conceptos puede lograrse sólo a partir de los procesos de abstracción y tiene sentido en la medida en que permite la construcción de estos últimos. En la definición de los conceptos seguimos a Davydov (s.f. : 48):

El concepto es un pensamiento en el que se reflejan los rasgos comunes y esenciales de los objetos y fenómenos de la realidad. Todo concepto se forma en nosotros sólo en unión de la palabra que le corresponde.

Al formar el concepto de los objetos y fenómenos de la realidad reflejamos sus rasgos comunes y substanciales. Tras destacar un determinado círculo de objetos y luego de advertir lo que en todos ellos hay de similar y distintivo, nuestro pensamiento singulariza el grupo de los indicios que forman el contenido del concepto de los objetos examinados.

De acuerdo con lo planteado, se puede percibir que el concepto aparece articulado a la palabra con la cual se designa el fenómeno que se expresa mediante este. Ello implica que al asumir la palabra como parte del concepto se deben tener en cuenta dos aspectos: Primero, la parte formal, mediante la cual se expresa con base en signos, símbolos y sonidos, y segundo, los contenidos a que hace referencia, en tanto que estos manifiestan los significados que tiene para el sujeto la realidad que representa. Por esto, y tal como lo plantea Vigostsky (1993: 287-347):

Una palabra carente de significado no es una palabra, es un sonido huero. Por consiguiente, el significado es el rasgo necesario, constitutivo de la propia palabra. El significado es la propia palabra vista desde su aspecto interno... el significado de la palabra no es más que una generalización o un concepto... Generalización y significado de la palabra son sinónimos. Toda generalización, toda formación de un concepto constituye el más específico, más auténtico y más indudable acto de pensamiento. Tenemos derecho a considerar el significado de la palabra como un fenómeno del pensamiento. El significado de la palabra es un 
fenómeno del pensamiento sólo en la medida en que el pensamiento está ligado a la palabra y encarnado en ella y viceversa.

En el mismo sentido, se hace evidente que tanto las expresiones formales, como los contenidos y significados de las palabras, y de los conceptos que ellas representan, manifiestan diferentes niveles de expresión y de comprensión, derivadas no sólo de la evolución de la realidad, sino de los niveles de desarrollo particular de los sujetos que los producen y manejan.

... los conceptos no son evidentemente fundamentales sólo para el método científico: constituyen los cimientos del todo el pensamiento y comunicación humanos. Sin embargo, puesto que la ciencia exige una mayor precisión en la comunicación, el proceso de conceptualización tiene que constituir una parte de la ciencia mucho más conscientemente que en el caso de la mayoría de los contextos de sentido común y cotidianos (Good, W. y Hatt, P. 1990: 59).

Por su parte, los signos, símbolos y sonidos mediante los cuales se expresan los conceptos, contienen significados que expresan los sentidos que tienen para los sujetos. Por tanto, bajo ninguna circunstancia se puede reducir el concepto a la manera como lo manifiestan los sujetos. Por ello, las comunicaciones deben trascender la formalidad de la construcción de los términos y buscar los sentidos históricos, culturales en los cuales se construyen y se utilizan.

De acuerdo con lo anterior, se ve necesario acceder a los conceptos sobre nuestro objeto de estudio, y contextuarlos en el conjunto de significaciones que le dan sentido no sólo a los contenidos, sino a la manera de presentarlos y a las conexiones como se construyen. Se trataría de evidenciar dominio sobre el concepto, lo que implica:

Dominar un concepto supone no conocer los rasgos de los objetos y fenómenos que el mismo abarca, sino también saber emplear el concepto en la práctica, saber operar con él... Domi- 
Las prácticas sociales cotidianas de jóvenes universitarios en la perspectiva de la ciudadanía - José Rubén Castillo García

nar un concepto supone dominar la totalidad de conocimientos sobre los objetos a que se refiere el concepto dado. Cuando más nos acerquemos a ello tanto mejor dominamos el concepto dado. En esto radica, pues, el desarrollo de los conceptos, que no permanecen invariables, sino que cambian en su contenido a medida que se amplían los conocimientos (Good, W. y Hatt, P. 1990: 27 y $31)$.

Las indicaciones anteriores se hacen con la intención de mostrar el sentido del desarrollo de la presente temática, puesto que se considera necesario abordar los conceptos existentes acerca del objeto del estudio, la configuración de la ciudadanía, penetrando en los diferentes puntos de vista que emiten los jóvenes al respecto. La objetivación del concepto se hace mediante un proceso discursivo que se apoya en las expresiones de los jóvenes universitarios acerca del asunto en mención.

De esta manera, se busca pasar por diferentes esferas relacionadas con el manejo de los conocimientos que evidencian dichos jóvenes acerca de ser ciudadano, empezando por los conceptos que ellos manifiestan acerca de la misma, y transitar hacia lo abstracto e imaginable, pasando por sus representaciones, dado que estos son los ámbitos en los cuales se centran nuestras indagaciones.

Para ello, se toma como referencia las prácticas sociales que surgen de la vida cotidiana, teniendo como base los componentes de dichas prácticas, que hemos dado en denominar las objetivaciones, los actores, los escenarios, las intencionalidades, las formas, las regularidades y la configuración. Desde allí se presentan sus puntos de vista acerca de lo que opinan los jóvenes universitarios sobre la ciudadanía.

Esta información se obtuvo en dos grupos de jóvenes universitarios: Estudiantes de la Universidad Autónoma de Manizales (322 estudiantes), y estudiantes de otras universidades públicas ubicadas en la ciudad de Manizales (153). 
Para ello, se consultó a los estudiantes mencionados, mediante la aplicación de una encuesta, en la cual se preguntaba a los jóvenes acerca de lo que entendían por ciudadano. El instrumento que se utilizó fue un cuestionario tipo cédula, puesto que estaba destinado para que fuese llenado por los mismos jóvenes, y contenía preguntas abiertas de diferente índole, pero para este estudio se aprovecharon las respuestas acerca de una de ellas: ¿qué es un ciudadano? Los datos obtenidos proporcionaron los conceptos de los jóvenes sobre este tópico. Luego fueron sistematizados mediante un cuadro, en el cual aparecían las categorías, con base en las cuales se leen sus prácticas sociales cotidianas sobre el tema en mención.

\subsection{Conceptos emitidos por los estudiantes} universitarios acerca de ¿qué es ser ciudadano? en la perspectiva de las prácticas sociales

\begin{tabular}{|c|c|c|c|c|c|c|c|}
\hline \multirow[b]{3}{*}{ Categorías } & \multirow[b]{3}{*}{ Concepto } & \multicolumn{3}{|c|}{$\begin{array}{c}\text { Estudiantes de las } \\
\text { universidades de } \\
\text { Manizales }\end{array}$} & \multicolumn{3}{|c|}{\begin{tabular}{|c|}
$\begin{array}{c}\text { Estudiantes de la Uni- } \\
\text { versidad Autónoma de } \\
\text { Manizales }\end{array}$ \\
\end{tabular}} \\
\hline & & \multicolumn{2}{|c|}{ Género } & \multirow[b]{2}{*}{ Total } & \multicolumn{2}{|c|}{ Género } & \multirow[b]{2}{*}{ Total } \\
\hline & & $\mathrm{M}$ & $\mathrm{F}$ & & $\mathrm{M}$ & $\mathrm{F}$ & \\
\hline \multirow{11}{*}{$\begin{array}{l}\text { Objetivaciones } \\
\text { Actos, acciones } \\
\text { procedimientos, } \\
\text { y conjuntos de } \\
\text { acciones que } \\
\text { hacen tangibles } \\
\text { las prácticas } \\
\text { sociales }\end{array}$} & Participación comunitaria & & & & 10 & 7 & 17 \\
\hline & Convivencia e interacción & & & & 6 & 0 & 6 \\
\hline & $\begin{array}{l}\text { Participar en las } \\
\text { decisiones }\end{array}$ & 1 & 4 & 5 & 8 & 12 & 20 \\
\hline & $\begin{array}{l}\text { Derecho a participar } \\
\text { políticamente }\end{array}$ & 1 & 0 & 1 & 3 & 1 & 4 \\
\hline & Acciones humanas & & & & 2 & 0 & 2 \\
\hline & Gobernar, dirigir, mandar & & & & 6 & 3 & 9 \\
\hline & Tener voz y voto & 1 & 0 & 1 & & & \\
\hline & $\begin{array}{l}\text { Participar con derechos } \\
\text { civiles dados por la ley, } \\
\text { elegir }\end{array}$ & 0 & 1 & 1 & 2 & 2 & 4 \\
\hline & $\begin{array}{l}\text { Participar en funciones } \\
\text { legislativas }\end{array}$ & 0 & 1 & 1 & & & \\
\hline & Total & 3 & 6 & 9 & & & \\
\hline & & & & Total & 37 & 25 & 62 \\
\hline
\end{tabular}


Las prácticas sociales cotidianas de jóvenes universitarios en la perspectiva de la ciudadanía - José Rubén Castillo García

\begin{tabular}{|c|c|c|c|c|c|c|c|}
\hline \multirow{13}{*}{$\begin{array}{l}\text { Actores de la } \\
\text { ciudadanía } \\
\text { Los que realizan } \\
\text { las prácticas } \\
\text { ciudadanas }\end{array}$} & $\begin{array}{l}\text { Persona con nacionalidad, } \\
\text { sercolombianoyserdelpaís }\end{array}$ & 1 & 1 & 2 & 5 & 2 & 7 \\
\hline & $\begin{array}{l}\text { Integrante de una } \\
\text { comunidad }\end{array}$ & 2 & 1 & 3 & 27 & 31 & 58 \\
\hline & Habitante & 1 & 2 & 3 & 8 & 2 & 10 \\
\hline & Participante & 0 & 1 & 1 & 1 & 0 & 1 \\
\hline & Grupo de personas & 0 & 1 & 1 & 22 & 12 & 34 \\
\hline & $\begin{array}{l}\text { Todo aquel se identifica } \\
\text { con cédula y/o } \\
\text { documento de identidad }\end{array}$ & 1 & 1 & 2 & 3 & 1 & 4 \\
\hline & $\begin{array}{l}\text { Mayor de } 18 \text { años, con } \\
\text { derechos y deberes }\end{array}$ & 1 & 3 & 4 & 5 & 0 & 5 \\
\hline & $\begin{array}{l}\text { Tener identidad, } \\
\text { calidad de ciudadano y } \\
\text { características propias }\end{array}$ & 1 & 1 & 2 & 7 & 8 & 15 \\
\hline & $\begin{array}{l}\text { Tener derecho adquirido, } \\
\text { aval y permiso para } \\
\text { actuar }\end{array}$ & & & & 17 & 10 & 27 \\
\hline & $\begin{array}{l}\text { Gente que conforma y son } \\
\text { miembros de... }\end{array}$ & & & & 14 & 10 & 24 \\
\hline & Personajes & & & & 1 & 1 & 2 \\
\hline & Total & 7 & 11 & 18 & & & \\
\hline & & & & Total & 110 & 77 & 187 \\
\hline \multirow{9}{*}{$\begin{array}{l}\text { Escenario } \\
\text { Ambiente en el } \\
\text { cual se realizan } \\
\text { las prácticas } \\
\text { sociales. Donde } \\
\text { las personas } \\
\text { llevan a cabo sus } \\
\text { vidas, construyen } \\
\text { vivencias, elaboran } \\
\text { experiencias } \\
\text { y generan } \\
\text { alternativas } \\
\text { de acción } \\
\text { relacionadas con la } \\
\text { ciudadanía. }\end{array}$} & Pueblo, población & 1 & 1 & 2 & 9 & 12 & 21 \\
\hline & Estado & 0 & 1 & 1 & 10 & 7 & 17 \\
\hline & $\begin{array}{l}\text { Fronteras, divisiones, } \\
\text { territorio, ciudad, } \\
\text { municipio, región, país }\end{array}$ & 1 & 1 & 2 & 61 & 43 & 104 \\
\hline & $\begin{array}{l}\text { Espacio geográfico, lugar, } \\
\text { sitio }\end{array}$ & 1 & 0 & 1 & 11 & 11 & 22 \\
\hline & Nación & & & & 0 & 1 & 1 \\
\hline & Total & 3 & 3 & 6 & & & \\
\hline & & & & & & & \\
\hline & & & & Total & 91 & 74 & 165 \\
\hline & & & & & & & \\
\hline
\end{tabular}




\begin{tabular}{|c|c|c|c|c|c|c|c|}
\hline \multirow{9}{*}{$\begin{array}{l}\text { Intencionalidades } \\
\text { Fines, lo que } \\
\text { interesa, lo que } \\
\text { se busca con la } \\
\text { realización de las } \\
\text { prácticas. }\end{array}$} & Exige y tiene derechos & 3 & 14 & 17 & 18 & 14 & 32 \\
\hline & Deberes & 1 & 6 & 7 & 15 & 10 & 25 \\
\hline & Ser hombre de Estado & 1 & 0 & 1 & & & \\
\hline & $\begin{array}{l}\text { Contribuir de manera } \\
\text { positiva o negativa en } \\
\text { el medio y resolver } \\
\text { problemas }\end{array}$ & 0 & 1 & 1 & 0 & 1 & 1 \\
\hline & $\begin{array}{l}\text { Realizar acciones para } \\
\text { beneficio mundial }\end{array}$ & 1 & 0 & 1 & & & \\
\hline & $\begin{array}{l}\text { Ayudar y apoyar a la } \\
\text { sociedad }\end{array}$ & & & & 4 & 2 & 6 \\
\hline & Lograr identidad & & & & 2 & 1 & 3 \\
\hline & Total & 6 & 21 & 27 & & & \\
\hline & & & & Total & 39 & 28 & 67 \\
\hline \multirow{8}{*}{$\begin{array}{l}\text { Formas } \\
\text { Artes, maneras de } \\
\text { hacer las cosas, } \\
\text { estilos }\end{array}$} & $\begin{array}{l}\text { Responsabilidad sobre } \\
\text { la ciudad, civismo, } \\
\text { colaboración, compromiso }\end{array}$ & 1 & 1 & 2 & 8 & 4 & 12 \\
\hline & Tener cualidades únicas & 1 & 3 & 4 & & & \\
\hline & $\begin{array}{l}\text { Respeto, acatar normas, } \\
\text { respeto de reglas y leyes, } \\
\text { atender los mandatos }\end{array}$ & 3 & 0 & 3 & 21 & 13 & 34 \\
\hline & $\begin{array}{l}\text { Saber cómo funciona } \\
\text { el Estado y la toma de } \\
\text { decisiones }\end{array}$ & 1 & 2 & 3 & & & \\
\hline & $\begin{array}{l}\text { Sentido patriótico, querer, } \\
\text { orgullo }\end{array}$ & & & & 2 & 2 & 4 \\
\hline & Estar de acuerdo & & & & 1 & 0 & 1 \\
\hline & Total & 6 & 6 & 12 & & & \\
\hline & & & & Total & 32 & 19 & 51 \\
\hline \multirow{6}{*}{$\begin{array}{l}\text { Regularidades } \\
\text { Hábitos y } \\
\text { costumbres }\end{array}$} & $\begin{array}{l}\text { Vivir por inercia como } \\
\text { robots }\end{array}$ & 1 & 0 & 1 & & & \\
\hline & $\begin{array}{l}\text { Vivir por el pueblo y para } \\
\text { el pueblo }\end{array}$ & 1 & 0 & 1 & & & \\
\hline & $\begin{array}{l}\text { Agremiarse, inscribirse, } \\
\text { vincularse y matricularse }\end{array}$ & & & & 3 & 1 & 4 \\
\hline & $\begin{array}{l}\text { Ser, hacer, formar, } \\
\text { pertenecer y sentirse parte } \\
\text { de..., }\end{array}$ & & & & 21 & 17 & 38 \\
\hline & Total & 2 & 0 & 2 & & & \\
\hline & & & & Total & 24 & 18 & 42 \\
\hline \multirow{5}{*}{$\begin{array}{l}\text { Configuración } \\
\text { Lo que le da } \\
\text { forma a las } \\
\text { prácticas sociales: } \\
\text { reglas, lógicas, } \\
\text { procedimientos, } \\
\text { coherencias }\end{array}$} & $\begin{array}{l}\text { Conocer los problemas } \\
\text { ciudadanos y } \\
\text { solucionarlos }\end{array}$ & 1 & 2 & 3 & 1 & 2 & 3 \\
\hline & $\begin{array}{l}\text { Tener la facultad de elegir } \\
\text { y ser elegido }\end{array}$ & 1 & 3 & 4 & 1 & 3 & 4 \\
\hline & $\begin{array}{l}\text { Estar informado e } \\
\text { interactuar }\end{array}$ & 0 & 1 & 1 & 0 & 1 & 1 \\
\hline & Total & 2 & 6 & 8 & & & \\
\hline & & & & Total & 2 & 6 & 8 \\
\hline
\end{tabular}


Las prácticas sociales cotidianas de jóvenes universitarios en la perspectiva de la ciudadanía - José Rubén Castillo García

Tal como puede observarse, las diversas opiniones expresadas por los jóvenes de la Universidad Autónoma de Manizales (UAM) y de los universitarios que estudian en la ciudad de Manizales, brindaron la posibilidad de ubicarlas de acuerdo con las categorías definidas y con base en ello se establecieron siete grupos de conceptos. Estos, porque son los que permiten mirar las prácticas sociales tomando como base las respuestas que brindaron y el significado de los contenidos expresados en las mismas. Es de aclarar que al respecto se procedió de la siguiente manera:

1) dadas las respuestas de los jóvenes, se identificaron las ideas que estaban dentro del texto, 2) se diferenciaron, y 3) se procedió a ubicarlas dentro de las categorías que se han establecido y que permiten configurar las prácticas sociales, en este caso, relacionadas con el ser ciudadano. En razón de ello, expresamos la presencia de sus conceptos de la siguiente manera, veamos:

Primero: con respecto de las objetivaciones, de los 475 estudiantes consultados, hubo $71(15 \%)$, cerca de la sexta parte de los consultados, que se refirieron a la ciudadanía en términos de los aspectos tangibles de las prácticas, más en la UAM (18,9\%), que en las otras universidades existentes en la ciudad, con 5,8\%. Se destaca ampliamente que los estudiantes que opinaron en este sentido, coinciden en definir lo ciudadano desde las diferentes expresiones de la participación. Hacen mención de la participación comunitaria, participar en las decisiones, participar con derechos civiles dados por la ley, derecho a participar politicamente, y participar en funciones legislativas.

Los índices al respecto están cercanos al 70\%. Ello nos permite decir que los jóvenes quieren incidir en la dinámica de la sociedad, que desean que se les tenga en cuenta, que es de su interés hacer uso del derecho a la participación, que quieren ser protagonistas, pero el asunto es que se hallan desencantados con las instituciones tradicionales, con sus rutinas y que, por el contrario, con estas dinámicas desean cambios rápidos donde los resultados sean notorios por su efectividad. En este sentido, se 
puede pensar que hay ciertos acuerdos de opiniones con los estudiantes universitarios que fueron consultados en Bogotá (2003), puesto que ellos expresaron que la ciudadanía tiene relación cercana con la participación:

Podemos observar que la mayoría de estudiantes (45\%) considera que la ciudadanía está presentada o asociada a la participación, y en segunda instancia (25\%), considera que la ciudadanía tiene que ver con la identidad y la pertenencia (Rojas, et al., 2005: 72).

En nuestro caso, lo expresó el 10\% del total de los estudiantes indagados, lo cual indica que, al menos, se puede sospechar que es un tema compartido por los grupos de estudiantes que se consultaron.

Segundo: dado que la pregunta se centró en solicitar el concepto sobre lo que entendían por ciudadano, interesa destacar que, en relación con las características que les plantean a los actores, es decir, a las personas que realizan las prácticas ciudadanas, se puede decir que los ven con dos posibilidades: una mayoritaria, donde los perciben organizados en colectivos, como parte de las comunidades donde actúan. El 56\% de los que se refirieron a este aspecto lo hicieron claramente en este sentido, con la posibilidad de reconocerse como ciudadanos a partir de su ejercicio social.

Desde la otra opción, se ve al ciudadano como el resultado de una cualidad individual, bien sea por ser un habitante, por reunir algunas calidades, o por tener un documento que les certifique condiciones como la edad y la nacionalidad, y a su vez, les permite hacer uso de las prebendas que ello consagra y que les permite desempeñarse como tales.

Por lo visto, la cédula de ciudadanía, según ellos, certifica a manera de título, que las personas que la posean tienen acceso a los derechos y a los deberes. Esto conduce a ver al ciudadano en relación con la organización política de la sociedad, el Estado, en 
Las prácticas sociales cotidianas de jóvenes universitarios en la perspectiva de la ciudadanía - José Rubén Castillo García

tanto que este ente es el encargado de oficializar dicho reconocimiento. En esta perspectiva, se percibe que los jóvenes consultados consideran la condición de ciudadano como resultado de las limitaciones, posibilidades y oportunidades que les brinda la sociedad o el Estado, tal vez pensado el asunto desde la perspectiva adultocéntrica.

Tercero: el 36\% de los jóvenes consultados refieren el ciudadano al escenario donde se realizan las prácticas sociales. Las opiniones expresadas contemplan dos aspectos: de un lado, los que se refieren al lugar, pensado como sitio donde ejercen las personas, ellos dicen que la ciudadanía se ejerce en sitios específicos como el país, la región, la ciudad o el municipio, mostrando con ello el territorio que habitan, donde nacieron o el lugar donde se desenvuelven cotidianamente $(27,1 \%$ del total y $75,4 \%$ de quienes asumieron esta posición); el otro aspecto, se remite a plantear la ciudadanía por la ubicación de los ciudadanos en los grupos sociales en donde actúan las personas, en ello coincidieron (8,8\% del total y $24,5 \%$ de los que escogieron esta opción) en señalar que el ciudadano está en relación con determinado conjunto social.

Estos puntos de vista nos remiten al pasado del concepto de ciudadano, en el primer caso, cuando los jóvenes los ven en términos del territorio al cual pertenecen o del lugar de donde provienen, como si fuera un fenómeno de ubicación, mientras que el segundo criterio nos acerca al tema de la polis griega, puesto que se mira al ciudadano inmerso en los grupos sociales donde se desenvuelve cotidianamente.

Como puede verse, los entrevistados definen al ciudadano con base en cuatro connotaciones diferentes: el territorio, el colectivo social, la organización política y la expresión cultural. Entre ellos predomina el primer punto de vista en el que vinculan al ciudadano condicionado por el territorio donde se desenvuelven. Le siguen los colectivos de habitantes, planteados como pueblo o población con el (4,8\% del total y $13,4 \%$ de los que se refirieron 
a esta opción). También son significativos los que muestran que el escenario donde se desempeña el ciudadano es la organización política, el Estado, con el 3,7\% del total y el 10,5\% de los que expresaron este punto de vista. En general, muestran que estas opciones son pensadas en forma mayoritaria por mujeres y que el ámbito de la ciudadanía cubre las diferentes esferas de la realidad social.

Cuarto: el concepto que tienen los jóvenes sobre la ciudadanía en función de los fines o de lo que se busca con las prácticas sociales, se manifiesta en 94 puntos de vista, que corresponden al 19,7\% de los que dieron la opinión en esta investigación. En este sentido, llaman la atención tres grupos de conceptos, que en el orden de presencia son: 1) los que consideran que ser ciudadano es ejercer los derechos (49, 10,3\% del total y 52,1\% de los que expresaron esta idea), 2) los que expresan que ser ciudadano es remitirse a los deberes sociales $(32,6,7 \%$ del total y $34 \%$ de los que asumieron esta postura), y 3) un grupo de jóvenes que ve al ciudadano en labores de apoyo a la sociedad $(9,1,8 \%$ del total y 9,5\% de los que eligieron estos puntos de vista). Si reunimos los conceptos que indican que ser ciudadano es ejercer desde los derechos y los deberes, podríamos pensar que en ellos se incluye algo más de la sexta parte de los jóvenes consultados.

De manera similar que el estudio desarrollado en la Universidad Distrital Francisco José de Caldas (Bogotá, agosto de 2004), aunque la mención de los derechos y deberes puede ser considerada baja, es muy posible que coincida con los resultados obtenidos allí en lo siguiente:

Derechos políticos y sociales. No obstante que la mención a este aspecto fue baja (10\%), a nivel de la argumentación, la mayoría de las respuestas de los estudiantes denotan un nivel conceptual de derechos políticos, sociales y civiles en el que hacen notar que la ciudadanía y la democracia van más allá del mero ejercicio del voto, reconociendo una serie de derechos y deberes democráti- 
Las prácticas sociales cotidianas de jóvenes universitarios en la perspectiva de la ciudadanía - José Rubén Castillo García

cos. Muchos de ellos son conscientes de su responsabilidad social como futuros profesionales de la educación y como agentes de cambio en la formación ciudadana y democrática. Así mismo, en las respuestas se refleja un nivel crítico de conciencia política al señalar los vicios tradicionales de nuestra clase política a través de los cuales se ven afectados los derechos de los ciudadanos (Rojas, et al. 2005: 73).

Quinto: algunos de los jóvenes ven al ciudadano a partir de las formas o maneras de serlo. Fueron 63 las opiniones que se dijeron en ese sentido, 13\% del total. Entre ellas se destacan básicamente dos opciones: 1) el sentido cívico, al cual se refirieron 19 de ellos ( $4 \%$ del total y $30 \%$ de los jóvenes que asumieron este punto de vista), y 2) el respeto por las normas, opinión que fue expresada por 63 jóvenes, es decir, el $8 \%$ del total y $60 \%$ de los que expresaron este criterio. Desde este punto de vista, se argumenta que la condición de ciudadano la logran aquellas personas que se acogen a las condiciones y calidades que se derivan de dar aplicación y uso adecuado a aquellas normas, reglas, leyes, mandatos por los cuales se rige el país.

De lo dicho, estos últimos conceptos encajan en una propuesta tradicional de pensar la ciudadanía, puesto que se considera que el individuo se ubica en la sociedad, determinado y sometido por las leyes que emanan de la institucionalidad y que le establecen funciones específicas como la adquisición de esa cualidad a partir de un límite de edad específico y el ejercicio de la ciudadanía, actuando mediante la participación en las elecciones. Las ideas anteriores se amplían con lo que manifiesta Herrera (2005: 52):

Dentro de esta tradición se es ciudadano en la medida en que se participe en los mecanismos diseñados por el Estado y por los sectores hegemónicos de la sociedad, por lo cual se otorga importancia a la formación de valores cívicos, como el respeto y acatamiento a las normas, para defender y fortalecer la democracia. El ideal de ciudadano que aquí circula, por ende, es un ciudadano virtuoso, dotado de atributos democráticos (compe- 
tencias democráticas), que tiene existencia en tanto sea reconocido por el Estado, que debe acatar las directrices que éste defina y que le permitan alcanzar tal estadio de desarrollo psicosocial. En este proceso de formación de ciudadanía priman aspectos relacionados con la moral del ciudadano, en tanto que a partir de la creación de un ser moral, el ciudadano moderno, se puede lidiar con las diferencias propias de cada individuo y consolidar así la idea de una sociedad armónica, característica del pensamiento burgués liberal de los siglos XVIII y XIX.

Sexto: Con respecto del ser ciudadano, los jóvenes que se refirieron a los hábitos y las costumbres, lo hicieron mediante las opiniones y conceptos de 44 de ellos $(9,2 \%$ del total de los investigados), y a partir de esto se identifican tres tipos de conceptos: 1) como estilo de vida, 2) por la vinculación a colectivos humanos, y 3) por la actuación en dichos grupos. La más significativa y diciente de ellas fue la tercera, puesto que se encontraron 38 opiniones que reflejaban este punto de vista ( $8 \%$ del total y $90 \%$ de las opiniones de este grupo de conceptos).

Este último criterio, en alguna medida, es coherente con lo expresado en otro ítem, en el sentido de que los jóvenes quieren participar, lo desean y por tanto, consideran que una persona es ciudadano si participa, y lo hace activamente, con responsabilidad y sentido de pertenencia en los diversos colectivos sociales.

Este conjunto de jóvenes plantea al ciudadano con base en lo que se puede denominar la afiliación y la pertenencia. En el primer caso, cuando definen esta cualidad de los sujetos tienen como base su vinculación, suscripción, matrícula, o agremiación a procesos en los cuales se realizan actividades tendientes a generar formas de acción social. Aunque no son muchos los jóvenes que conceptúan de esta manera, quienes lo hacen evidencian que la ciudadanía es un elemento fundante en la construcción de los colectivos a partir de los conceptos de nosotros y de los otros, es decir, que a partir de esta condición social de los sujetos, algunos se inscriben como sujetos particulares y además se sienten colec- 
Las prácticas sociales cotidianas de jóvenes universitarios en la perspectiva de la ciudadanía - José Rubén Castillo García

tivos al asumirse como parte de los grupos sociales. Es de anotar que otros individuos y grupos sociales no tienen esa posibilidad porque son excluidos, y quizás silenciados, por carecer de reconocimiento, aceptación y oportunidades.

Dentro de esta categoría, un grupo mayor de jóvenes, además de sentirse ubicados en un conglomerado social, bien sea pensados como procedentes de un lugar o de un colectivo social, trascienden la ciudadanía como efecto de la localización y se perciben como tales pensando en sus posibilidades de participar en actividades propias de y para ellos. Esta pertenencia, además, se reconfirma cuando se sienten cobijados por los grupos, como parte de esos conglomerados y además buscan aparecer registrados y reconocidos por una entidad formal que haga parte de la sociedad.

Séptimo: al mirar los conceptos de los jóvenes sobre la calidad del ciudadano, desde lo que le da forma o configura las prácticas sociales, son muy pocas las opiniones al respecto, al punto que se pudieron ubicar sólo 16 expresiones referidas a ello (3,3\% del total), con base en las cuales se indican algunos procedimientos de acción como tipificadas para los ciudadanos. Entre ellas, se pueden mencionar conocer los problemas ciudadanos y solucionarlos, tener la facultad de elegir y ser elegido y estar informado e interactuar, se distingue un poco el planteamiento relacionado con las posibilidades de hacer uso del derecho de elección tanto de sí mismos como de otros.

\section{A manera de conclusión}

Acerca de los conceptos emitidos por los jóvenes sobre el ser ciudadano, se puede encontrar el deseo de participar en la construcción de la sociedad. En ese sentido, perciben al ciudadano vinculado a colectivos sociales más que a los asuntos individuales. Además, se observa que en ellos es importante que se les reconozca formalmente como ciudadanos e incluso que haya un 
documento donde se certifique no sólo su calidad de tales, sino el reconocimiento de sus derechos, este usualmente es la cédula de ciudadanía.

Predomina la referencia del ciudadano a un territorio físico, más que a los grupos sociales, lo cual aparece como un contrasentido con lo dicho anteriormente, pero se trata de que se les ubique a partir de un lugar físico, desde el cual se les identifique como ciudadanos de alguna parte, y luego por las acciones que realizan en los grupos en los cuales se desempeñan en los diferentes ámbitos de la vida en diferentes campos de la realidad, bien sea en lo social, lo político y lo cultural.

También se preocupan porque la ciudadanía les permita acceder a los derechos y a los deberes. Además, expresan la importancia de que el ciudadano sea respetuoso de las normas sociales, y de que actúen de acuerdo con las funciones que desde ellos se les asignen. Al respecto, quedan algunas inquietudes, puesto que la ciudadanía, tal como lo plantea Aguilar (1998: 154), no puede verse exclusivamente desde la óptica de la ciudadanía legal otorgada a los mayores de edad, sino que debe adquirir un carácter social y político en la escuela. Desde este ángulo, se entenderá que el niño forma parte de un conglomerado social donde crea sentido de pertenencia a una organización micropolítica en la cual forma hábitos de participación en lo público.

Las prácticas sociales, vistas con base en los hábitos y las costumbres, muestran que los jóvenes se interesan por formalizar su calidad de ciudadano desarrollando diversos procesos de afiliación, de vinculación e incluso de matrícula y de registro a los grupos sociales, además que, según ellos, deben generar pertenencia con respecto de estos. Aunque son muy pocos los conceptos sobre las expresiones que permiten configurar las prácticas ciudadanas, se percibe la necesidad de que conozcan los problemas ciudadanos para poder solucionarlos, y de tener la opción de elegir y de ser elegidos. 
Las prácticas sociales cotidianas de jóvenes universitarios en la perspectiva de la ciudadanía - José Rubén Castillo García

En este sentido, compartimos el punto de vista de Aguilar y Caballero (s.f.: 17) cuando reflexionan sobre la ciudadanía y la calidad del ciudadano:

Cuando hablamos de ciudadanía nos estamos refiriendo a un proceso y, por lo tanto, a una dinámica social, en sentido histórico, de cambio y de movimiento. Pero la ciudadanía es un proceso que tiene un objetivo que no es otro que la construcción de una condición: la de ciudadano. El ciudadano es el sujeto que tiene derechos y deberes políticos y, en consecuencia, la responsabilidad sobre la gobernabilidad de una ciudad, de una nación, de un Estado. La polis es el lugar ocupado (el hábitat) y apropiado por el sujeto que desarrolla derechos y deberes políticos como estrategia para satisfacer las necesidades humanas.

Se entiende necesariamente formada la ciudad en el momento mismo en que la masa políticamente asociada puede proveer a todas las necesidades de su existencia. Más allá de este límite, la ciudad puede aún existir en más vasta escala, pero esta progresión, lo repito, tiene sus límites. [Aristóteles].

La ciudadanía, por consiguiente, tiene que ver con las diversas maneras de ejercer dicha condición, que en ella se evidencian diferentes matices, entre los que se destacan aquellos que dicen que es a través de conocer los problemas ciudadanos y solucionarlos, saber cómo funciona el Estado y la toma de decisiones, estar informado e interactuar. Otra forma de ejercer los derechos tiene que ver, según los jóvenes, con el uso de mecanismos de participación, de lo cual se desprende cierto énfasis al opinar que hay que tener facultad para elegir y ser elegido, tienen voz y voto, aunque otro grupo de opiniones relacionan la ciudadanía con el tema de la participación, cuando dicen: participar activamente en las decisiones del gobierno, participar con derechos civiles dados por la ley, participar en funciones legislativas, y ejercer los derechos de participar activamente.

Tal como se indicaba al principio de este texto, es necesario para el presente estudio mostrar los conceptos que tienen los jó- 
venes acerca del ser ciudadano y, a partir de ello, mirar sus puntos de vista desde la configuración que puede realizarse con referencia de las prácticas sociales. Esto desde lo que ellos piensan, opinan y manifiestan. El asunto es que los jóvenes consultados muestran sus deseos de ser actores y protagonistas de la vida social, que actúan y se desenvuelven en la vida cotidiana buscando ganar espacios de participación, pero sienten que las instituciones les ofrecen serias dificultades para lograr lo que desean en ese sentido Reguillo (2000: 1) plantea:

En América Latina, los testimonios cotidianos que evidencian su irrenunciable búsqueda de una sociedad más inclusiva y democrática se estrellan contra el creciente deterioro económico, la incertidumbre y la fuga del futuro. El debilitamiento de los mecanismos de integración tradicional (la escuela y el trabajo, centralmente) aunado a la crisis estructural y al descrédito de las instituciones políticas, genera una problemática compleja en la que parecen ganar terreno la conformidad y la desesperanza, ante un destino social que se percibe como inevitable.

Es en este contexto donde adquiere relevancia la pregunta por las formas organizativas juveniles, por sus maneras de entender y ubicarse en el mundo, por los diversos modos en que se asumen ciudadanos.

Los jóvenes se han autodotado de formas organizativas que actúan hacia el exterior -en sus relaciones con los otros- como formas de protección y seguridad ante un orden que los excluye y que, hacia el interior, han venido operando como espacios de pertenencia y adscripción identitaria, a partir de los cuales es posible generar un sentido en común sobre un mundo incierto.

Lo anterior, nos ubica en la necesidad de indagar acerca de escenarios y de las expresiones organizativas, de los mecanismos de participación de los jóvenes, mediante los cuales buscan alcanzar respaldo, reconocimiento, identidad, pertenencia e incluso protección, y desde los cuales se proyectan a la vida colectiva. 
Las prácticas sociales cotidianas de jóvenes universitarios en la perspectiva de la ciudadanía - José Rubén Castillo García

\section{Bibliografía}

Aguilar, Juan Francisco (1998). De viajes, viajeros y laberintos, Bogotá, IDEP, INNOVE.

Aguilar, Tusta y Caballero, Araceli (coordinadoras) (s.f.). Campos de juego de la ciudadanía. Editorial el Viejo Topo. Impreso en España. Imprime Novagrafik, S.A.

Berger, P., Luckman, T. (1978). La Sociedad como Realidad Subjetiva. En: La Construcción Social de la Realidad. Buenos Aires: Amorrortu.

Davydov, V. (s.f.). Tipos de Generalización en la enseñanza. Editorial Pueblo y Educación. Ciudad de La Habana. S.N.T.

Fernández, Hugo Oscar. oscarfer@mdq.com.ar. Acerca de Foucault y las Prácticas Sociales. En: www.fuentes.csh.udg.mx/CUCSH/ Sincronia/fernandez.htm.

Good, W. y Hatt, P. (1990). Elementos fundamentales del método científico: los conceptos. En: Métodos de Investigación Social. Editorial Trillas, México.

Habermas, Jürgen (1987). Problemática de la Comprensión en Ciencias Sociales. En: Teoría de la Acción Comunicativa. Madrid, vol. 1.

Heller, Agnes (1991). Sociología de la vida cotidiana. Traducción de J. F. Yvars y E. Pérez Nadal. Ediciones península, $3^{\text {a }}$ edición, mayo de 1991. Barcelona, España.

Herrera, Martha Cecilia; Pinilla Díaz, Alexis V.; Infante Acevedo, Raúl; y Díaz Soler, Carlos J. (2005). La construcción de la cultura política en Colombia. Proyectos hegemónicos y resistencias culturales. Universidad Pedagógica Nacional. $1^{\mathrm{a}}$. Edición.

Melich, Joan Carles (1996). Del extraño al cómplice. Editorial Antrophos. Barcelona.

Moser, Heins (1978). La Investigación-Acción como nuevo Paradigma en las Ciencias Sociales. En: Crítica y Política en Ciencias sociales. El Debate Teoría y práctica. Simposio Mundial de Cartagena. Editorial Punta de Lanza, tomo I.

Reguillo Cruz, Rossana (2000). Emergencia de culturas juveniles. Estrategias del desencanto. Enciclopedia Latinoamericana de Sociocultura y Comunicación. Grupo editorial NORMA, Buenos Aires.

Ricoeur, Paul (1975). Ciencia e ideología. En: Ideas y Valores No. 4245, 19731975. Revista del Departamento de Filosofía y Humanidades de la Universidad Nacional. Medellín. 
Ritzer, George. Teoría Sociológica Moderna. Quinta edición. McGraw Hill Interamericana de España, S.A.U.

Rojas Trujillo, Guillermo; Bogoya, Nelly; Ojeda, Lina Margarita; Segura, María Helena y Santana Gaitán, Carlota (2005). Educación y desarrollo personal de los licenciados de la Universidad Distrital. Formación en Valores ciudadanos y democráticos. Universidad Pedagógica Nacional.

Vigotsky, L. S. (1993). Obras Escogidas Tomo II. "Pensamiento y Lenguaje". Conferencias sobre Psicología. Edición en lengua Castelllana: Amelia Álvarez y Pablo del Río. Ed. Visor. Madrid.

Weber, Max (1969). Acción Social, en: Estrada Ospina, Víctor Mario; Becerra Mejía, Oscar y otros. Las Prácticas Universitarias Estudiantiles. Una Estrategia para la Modernización de la Educación Superior en Colombia. Universidad del Valle e ICFES. 